\title{
Synthesis of a Macrocycle Bearing a Carbon Framework of [16]Cyclophenacene as a Carbon Nanobelt
}

\author{
Shuangjiang Li and Kung K. Wang* \\ C. Eugene Bennett Department of Chemistry, West Virginia University \\ Morgantown, West Virginia 26506-6045, United States
}

\section{Supporting Information}

\section{Table of Contents}
Page
S2-S3 $\quad{ }^{1} \mathrm{H}$ and ${ }^{13} \mathrm{C}$ NMR Spectra of $\mathbf{1 0}$
S4 $\quad{ }^{1} \mathrm{H}$ NMR Spectra of $\mathbf{1 2}$
S5-S6 $\quad{ }^{1} \mathrm{H}$ and ${ }^{13} \mathrm{C}$ NMR Spectra of $\mathbf{1 4}$
S7-S8 $\quad{ }^{1} \mathrm{H}$ and ${ }^{13} \mathrm{C}$ NMR Spectra of $\mathbf{1 6}$
S9-S10 $\quad{ }^{1} \mathrm{H}$ and ${ }^{13} \mathrm{C}$ NMR Spectra of $\mathbf{1 7}$
S11-S12 $\quad{ }^{1} \mathrm{H}$ and ${ }^{13} \mathrm{C}$ NMR Spectra of $\mathbf{1 8}$
S13-S14 $\quad{ }^{1} \mathrm{H}$ and ${ }^{13} \mathrm{C}$ NMR Spectra of $\mathbf{1 9}$
S15-S16 $\quad{ }^{1} \mathrm{H}$ and ${ }^{13} \mathrm{C}$ NMR Spectra of 4
S17-S18 $\quad{ }^{1} \mathrm{H}$ and ${ }^{13} \mathrm{C}$ NMR Spectra of 5 


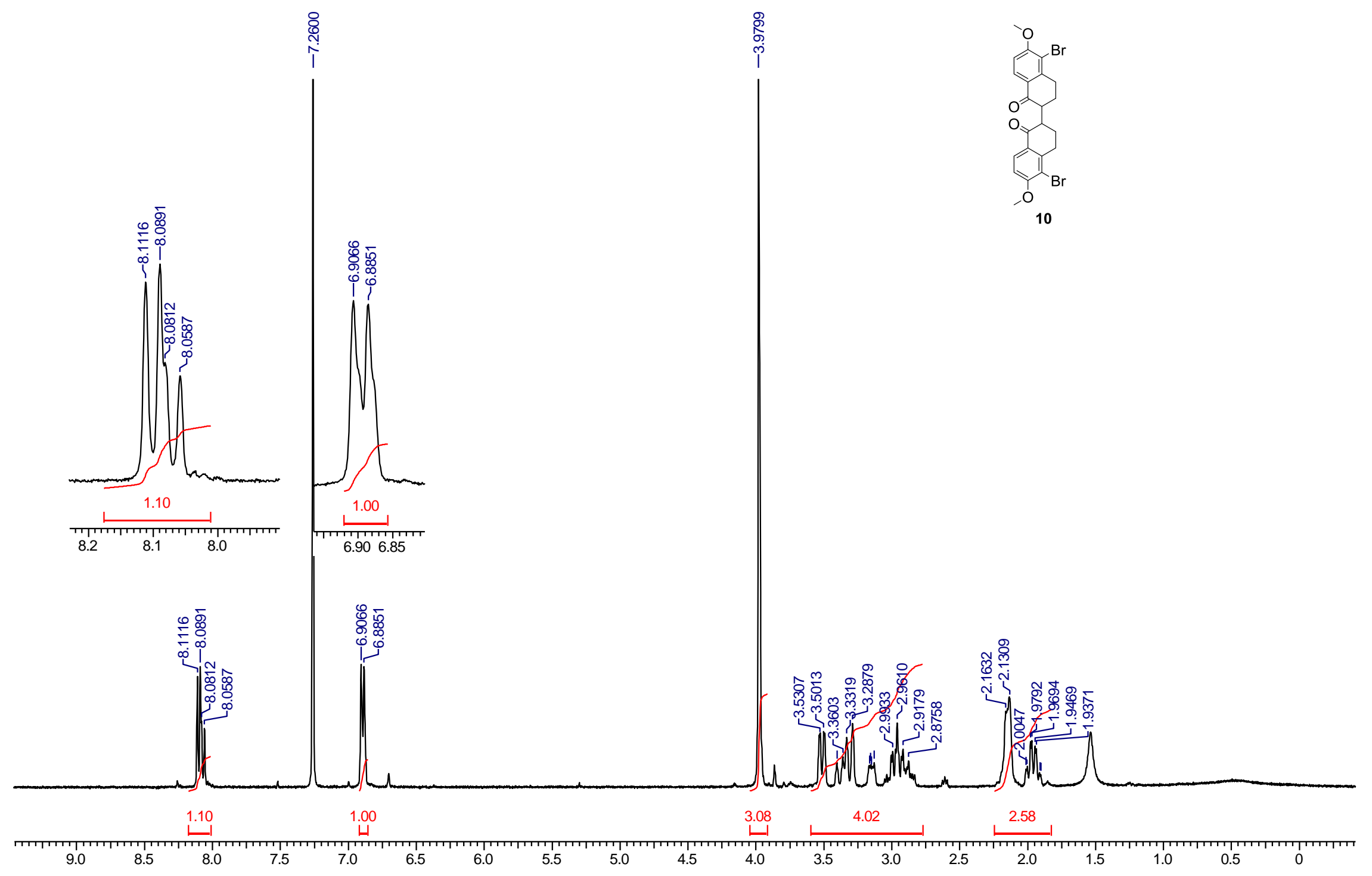




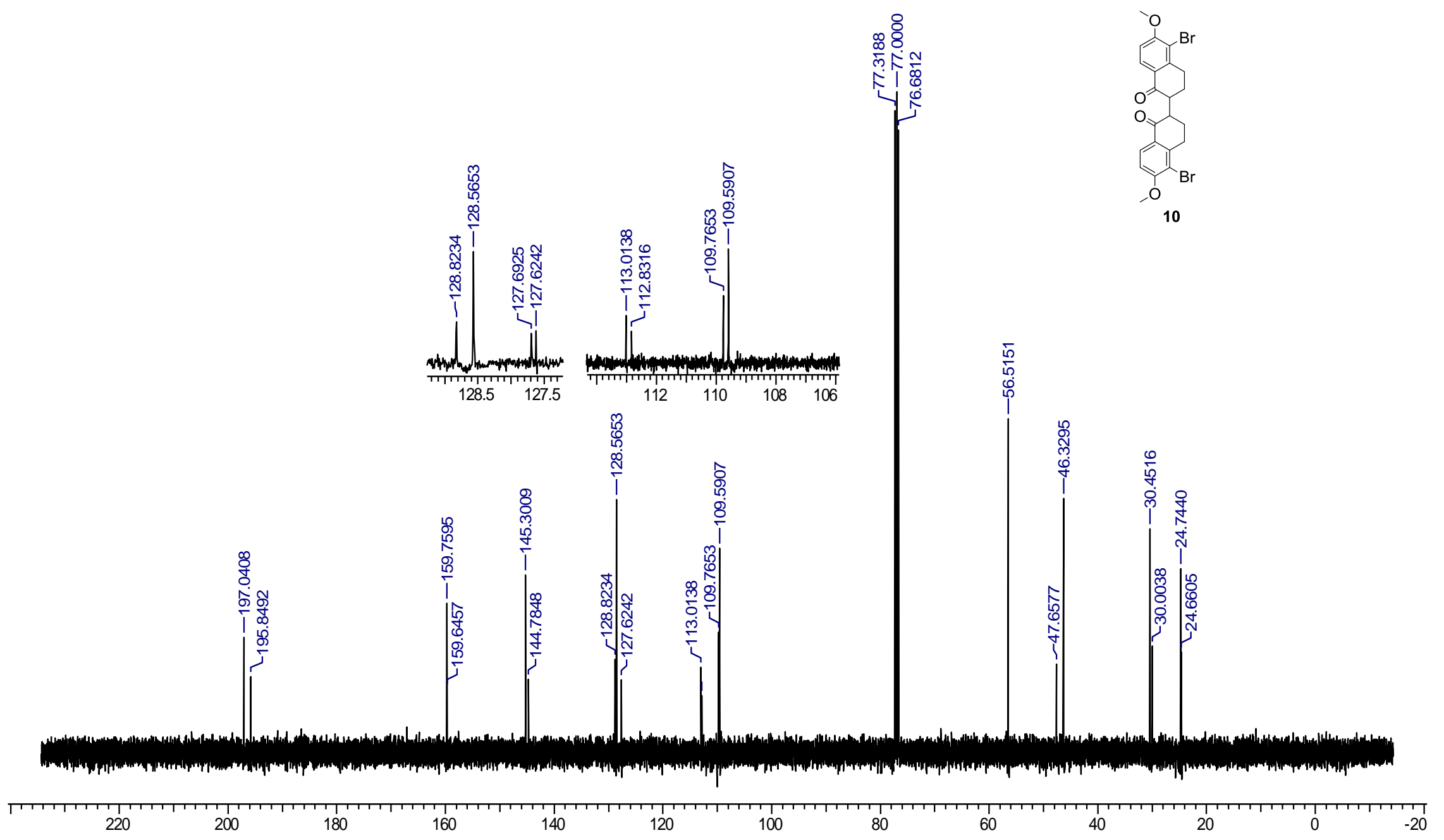



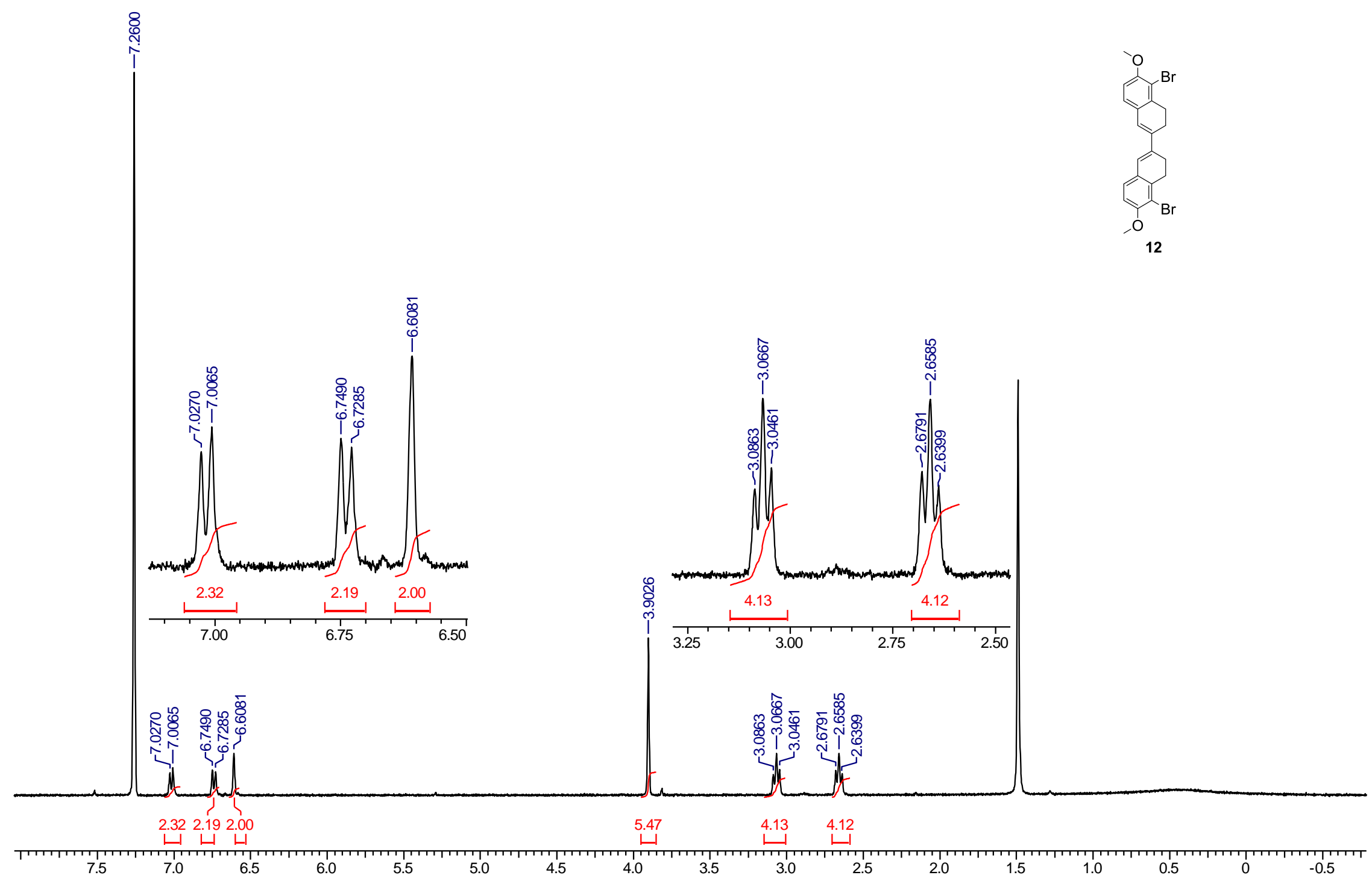


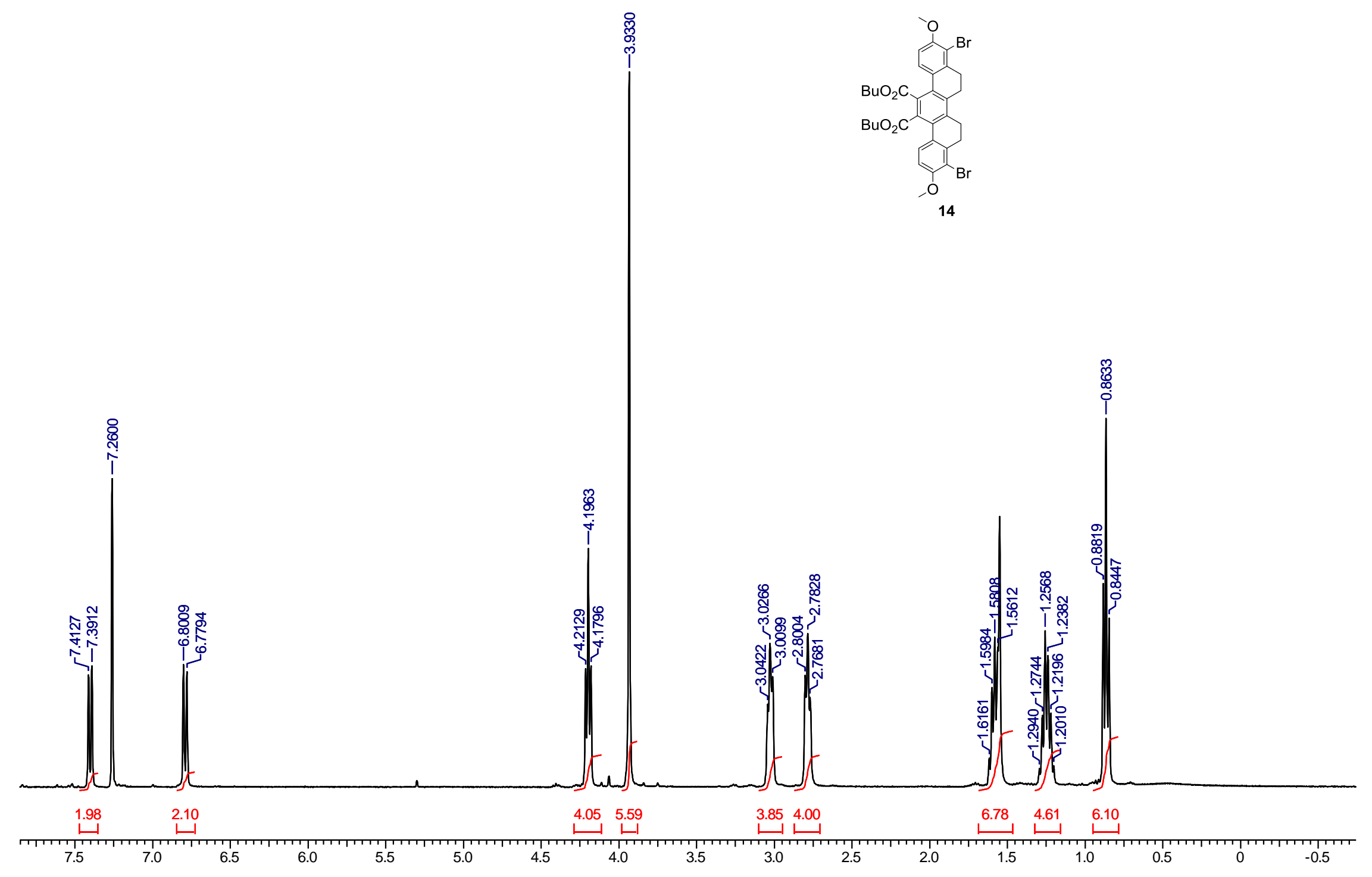



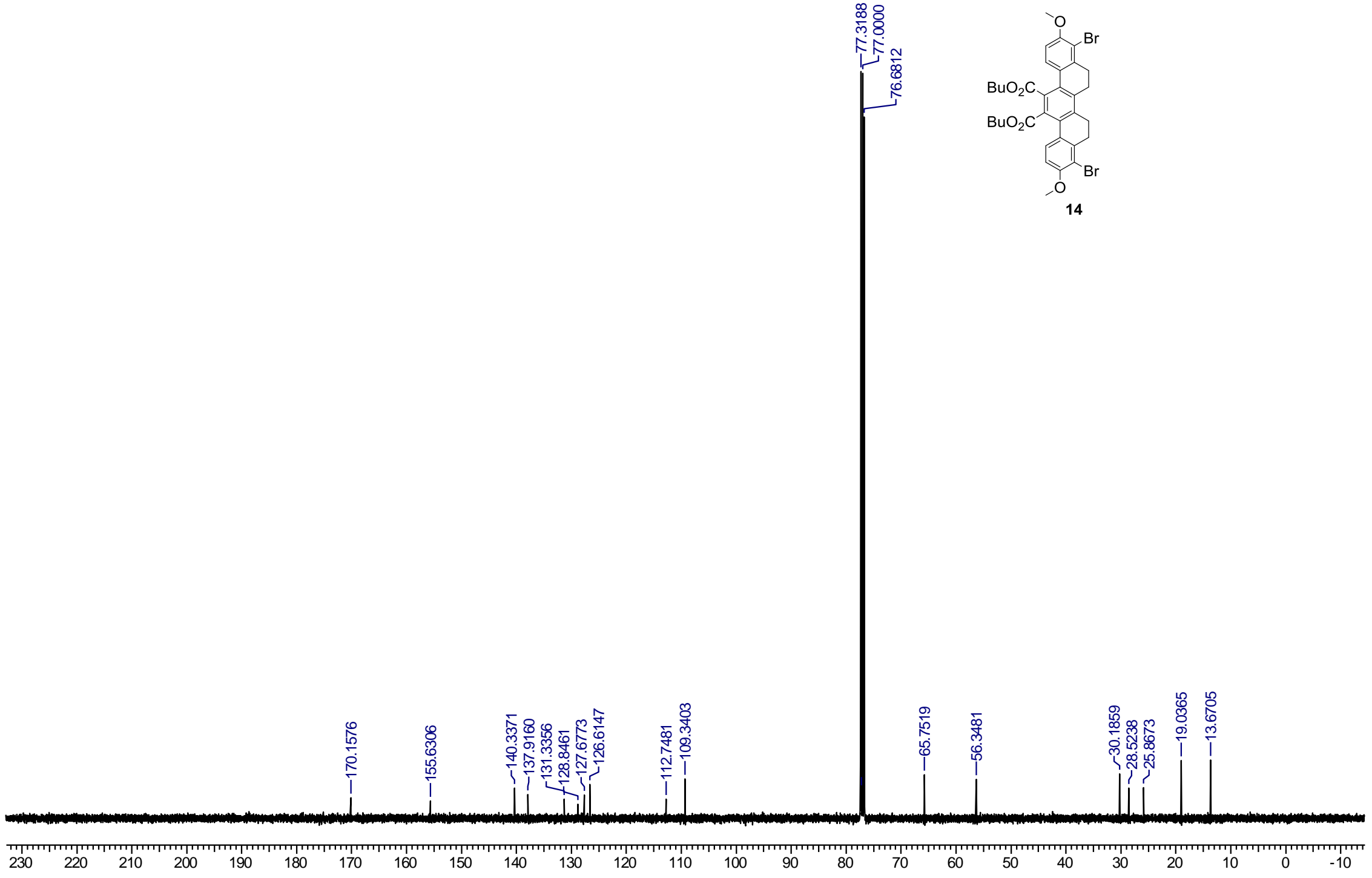

S6 


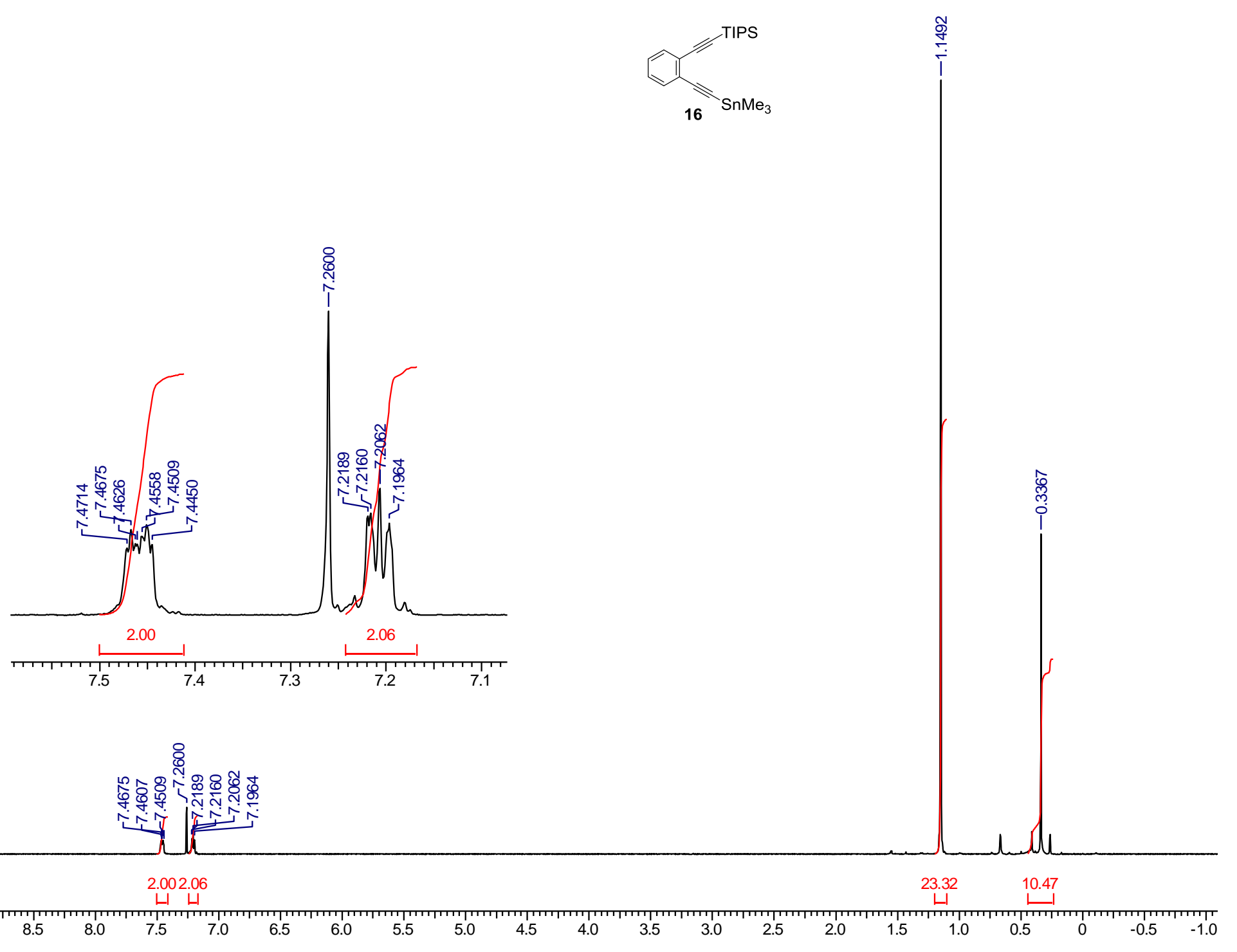




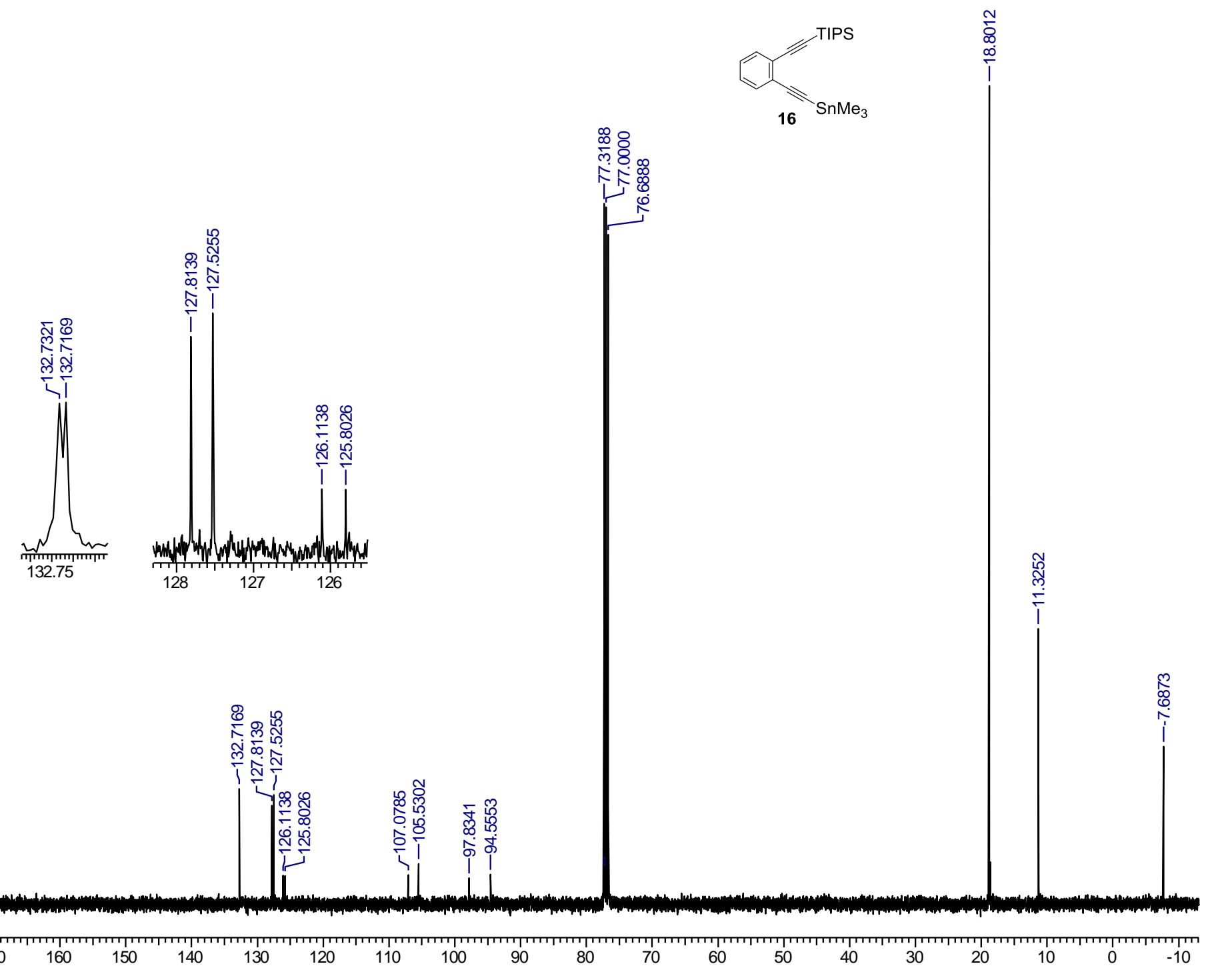




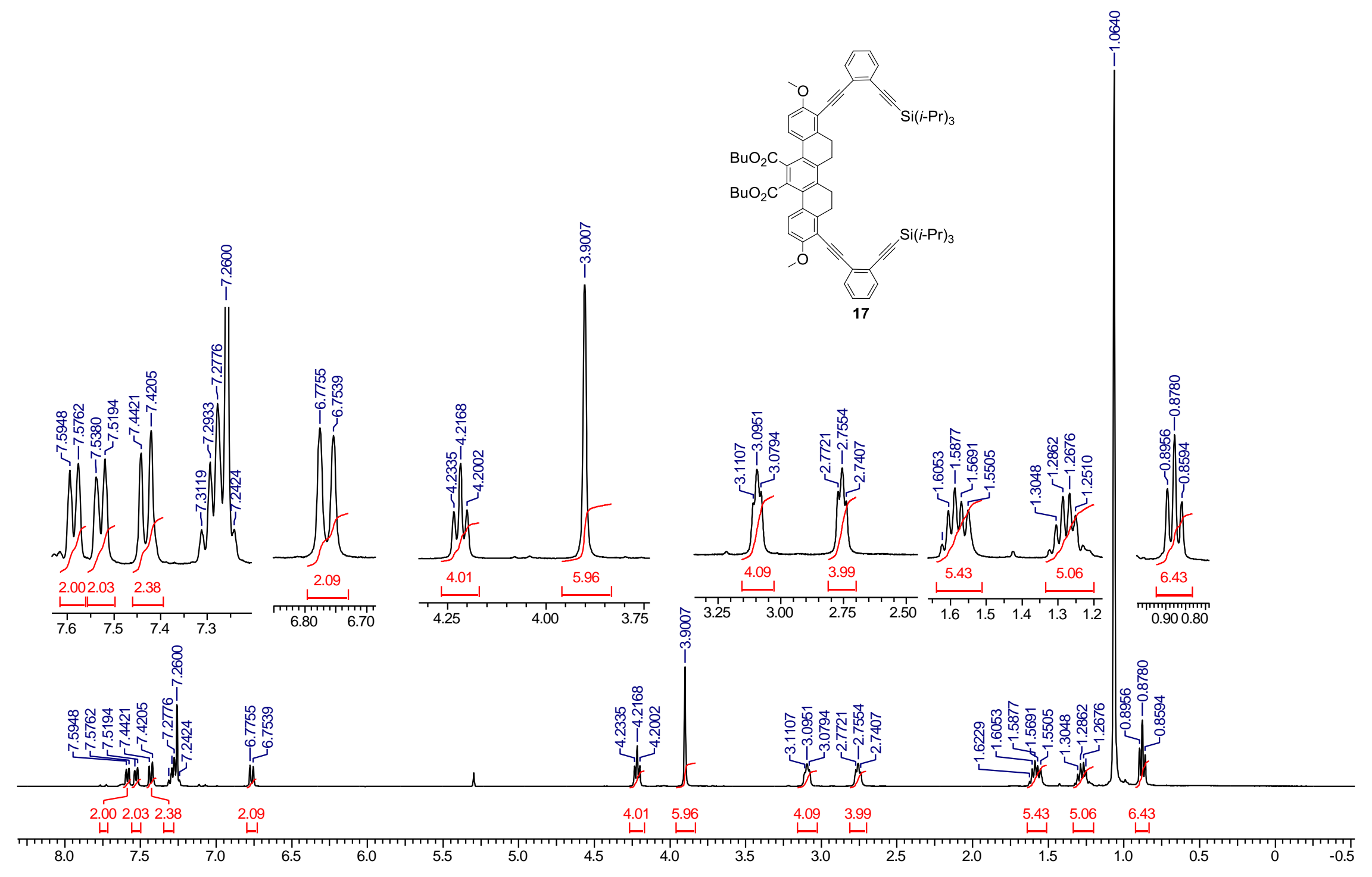




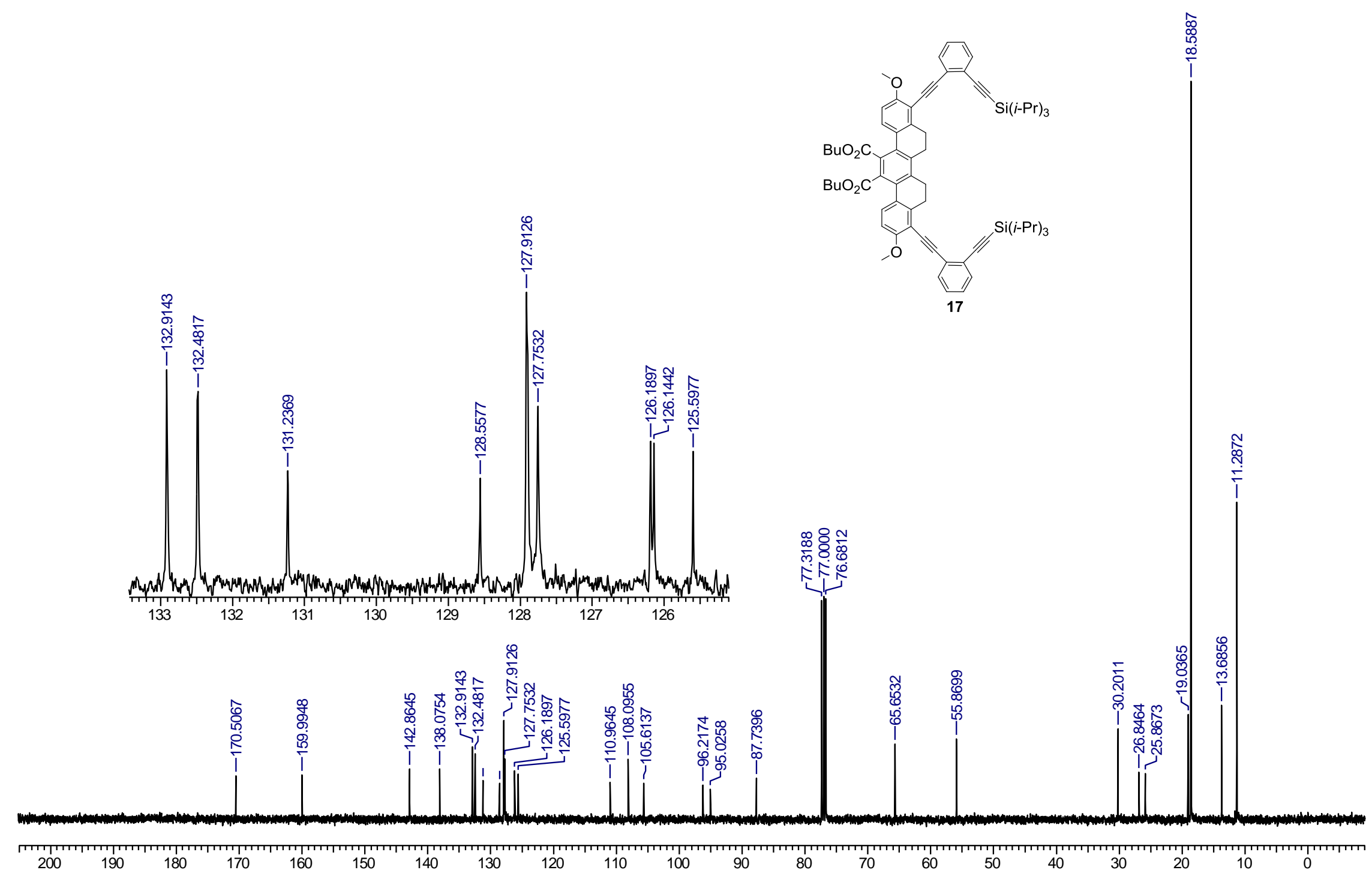




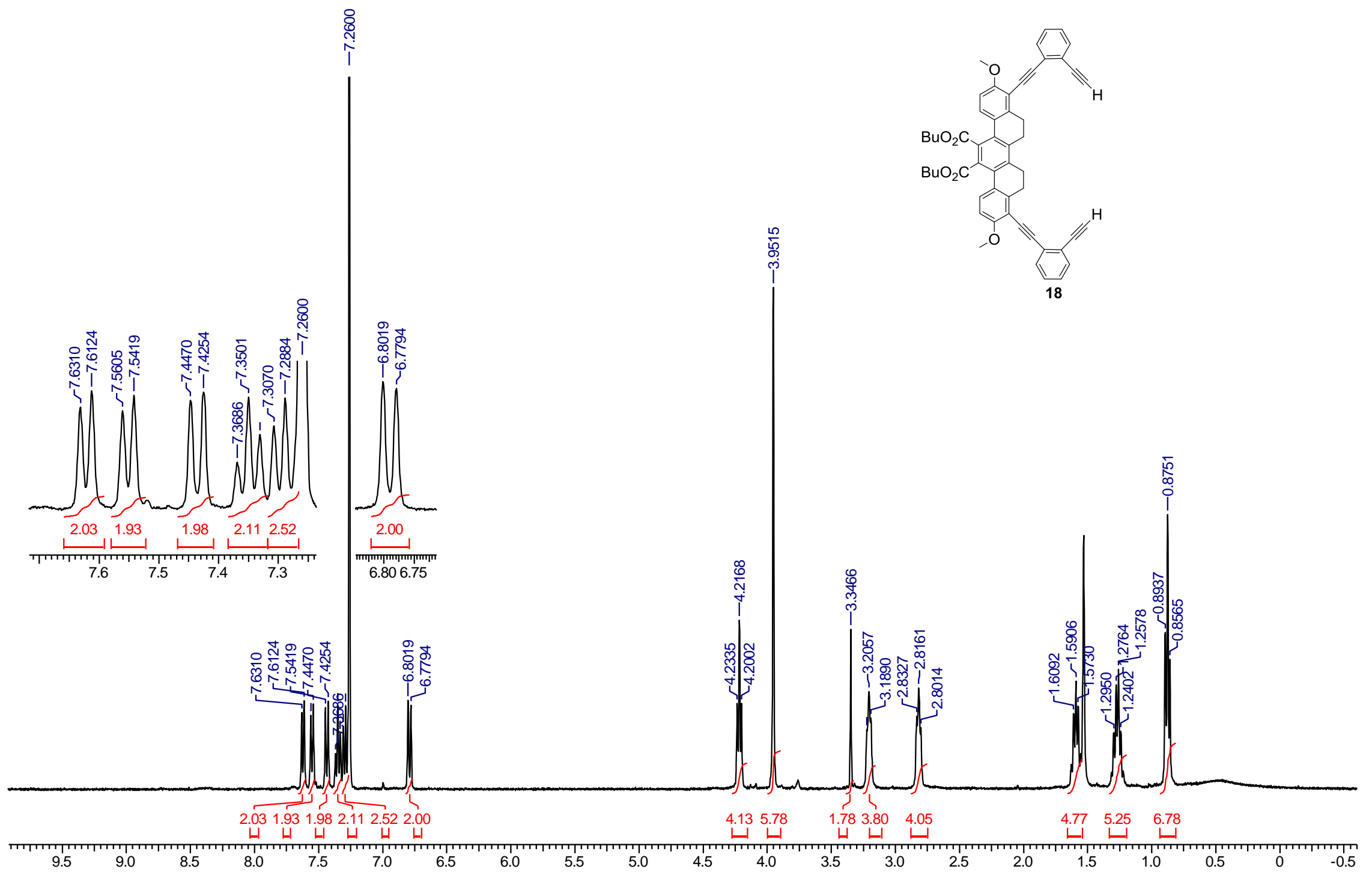




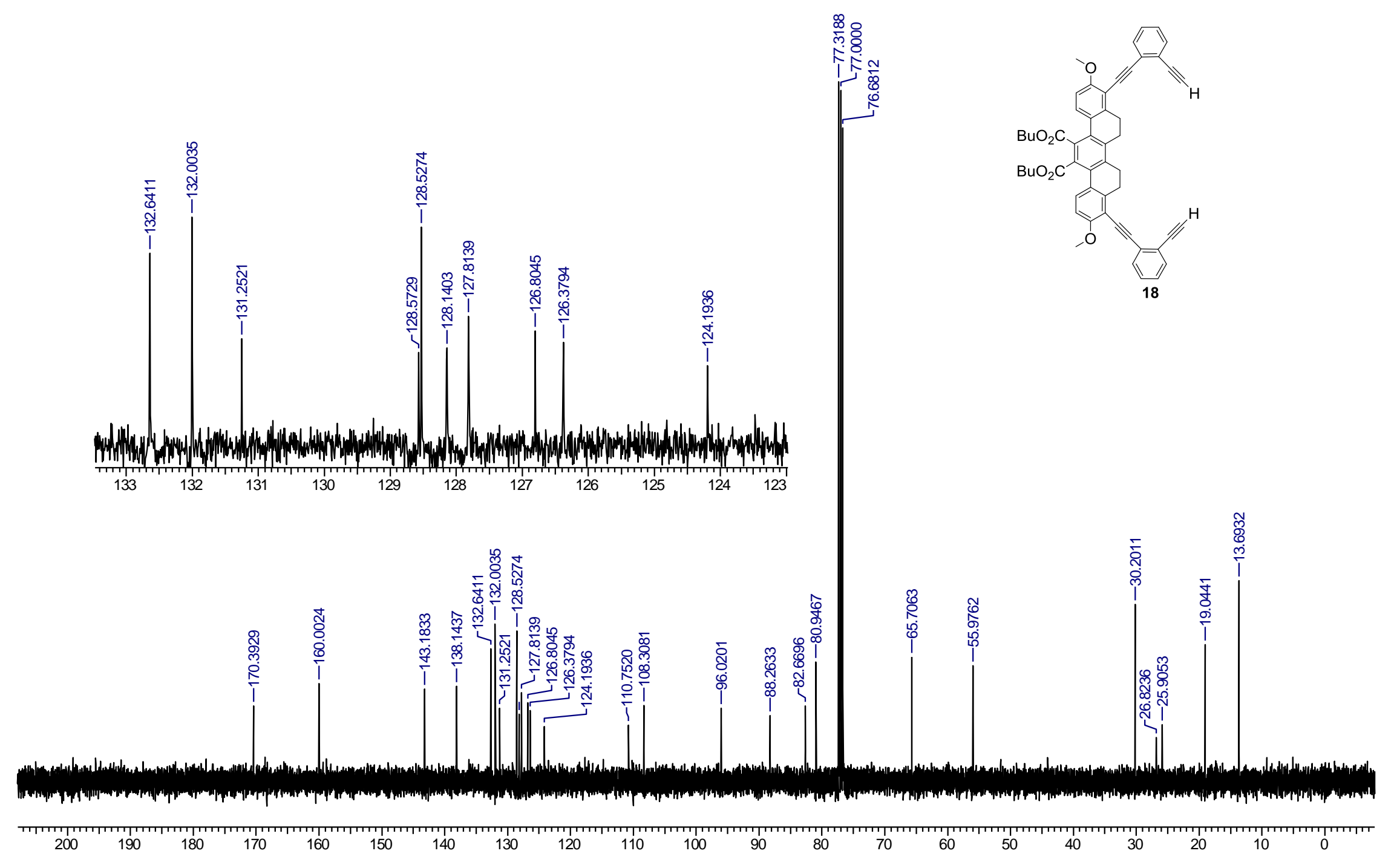




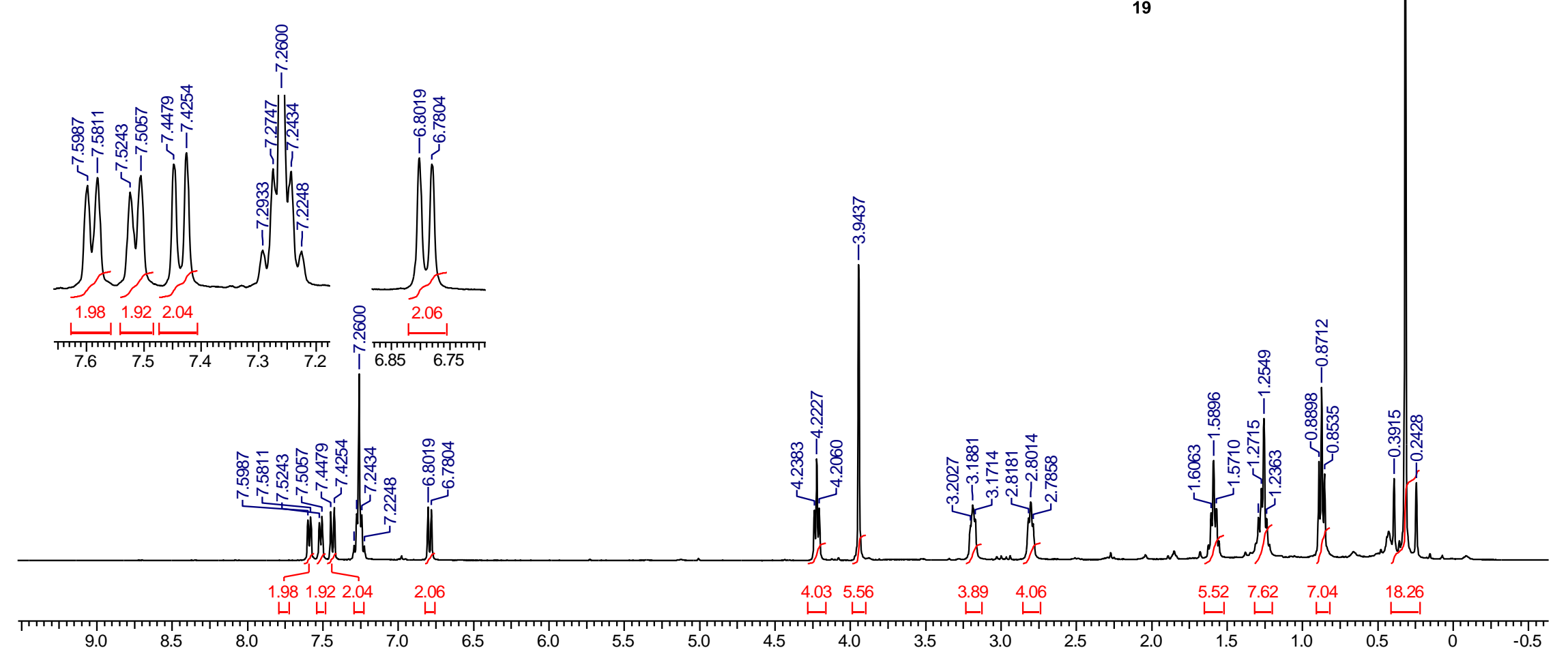



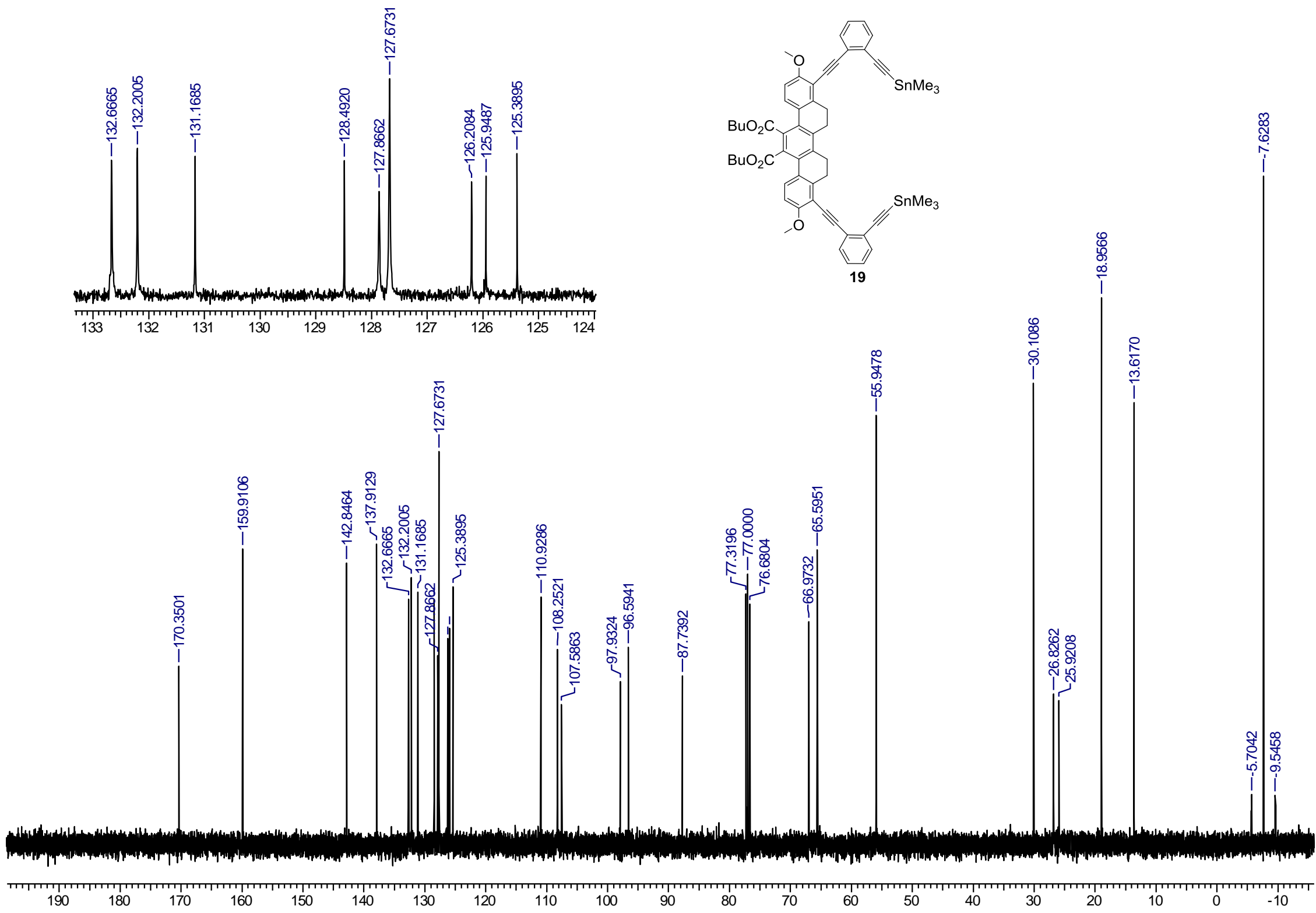


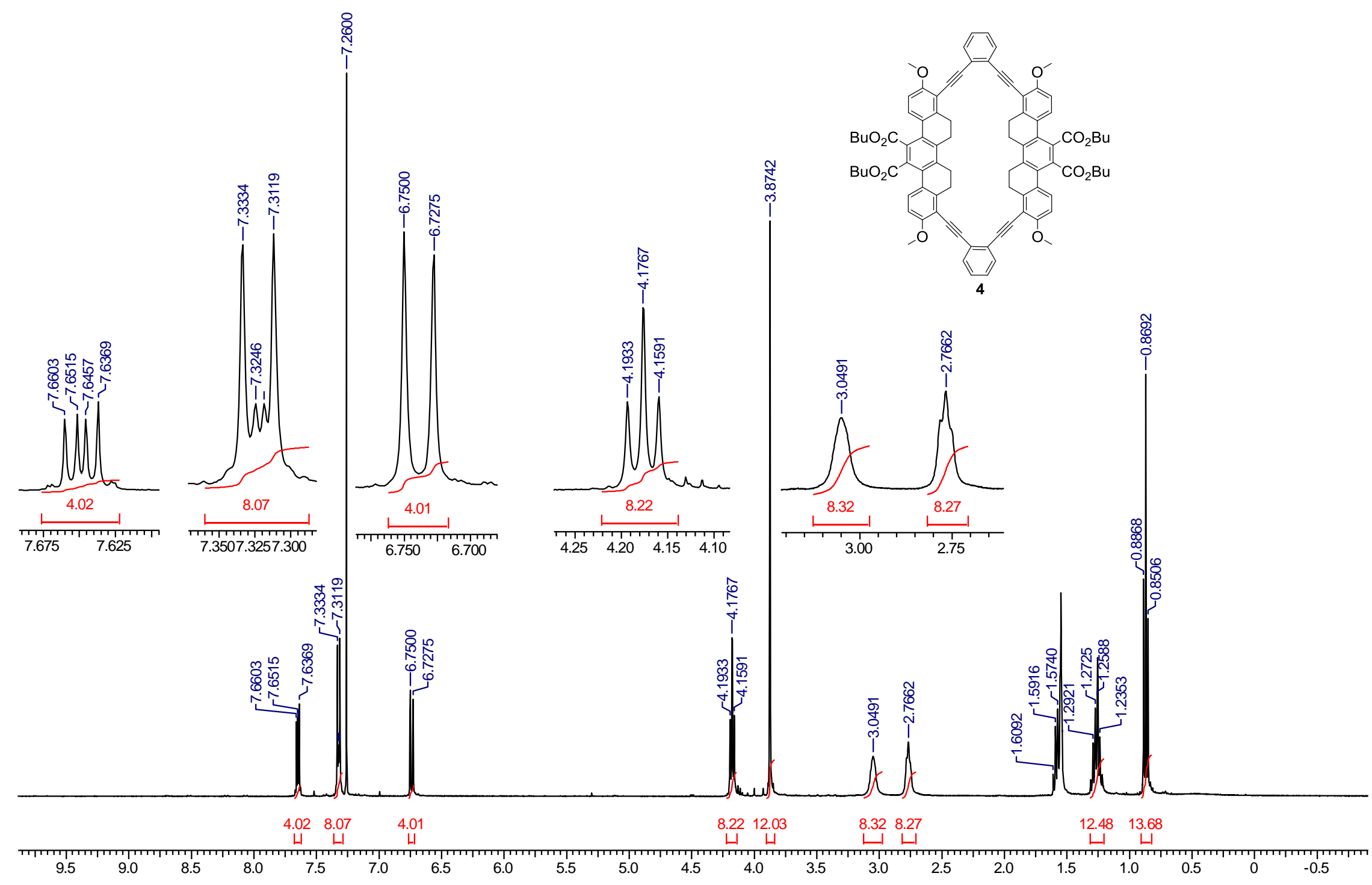




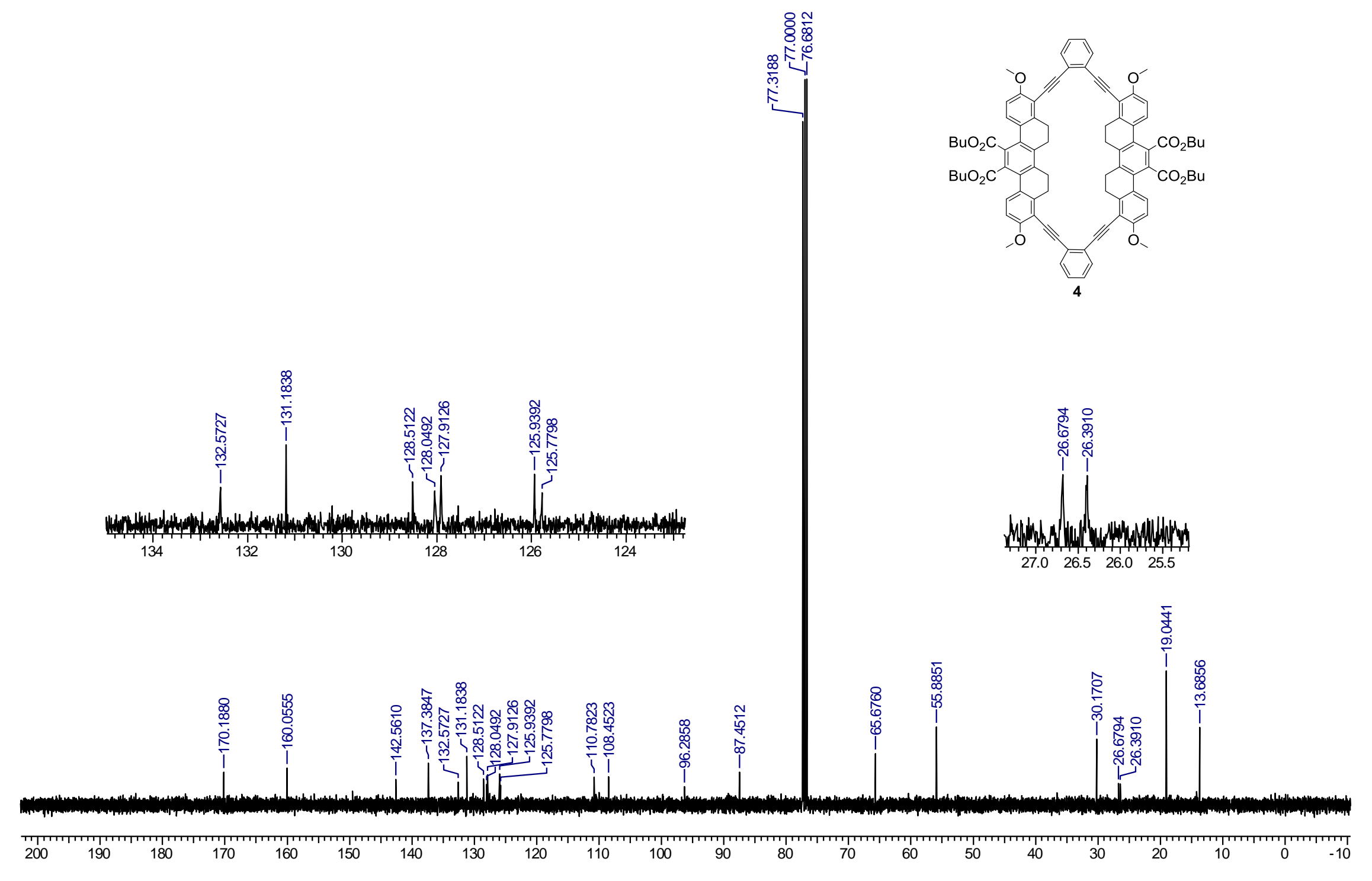




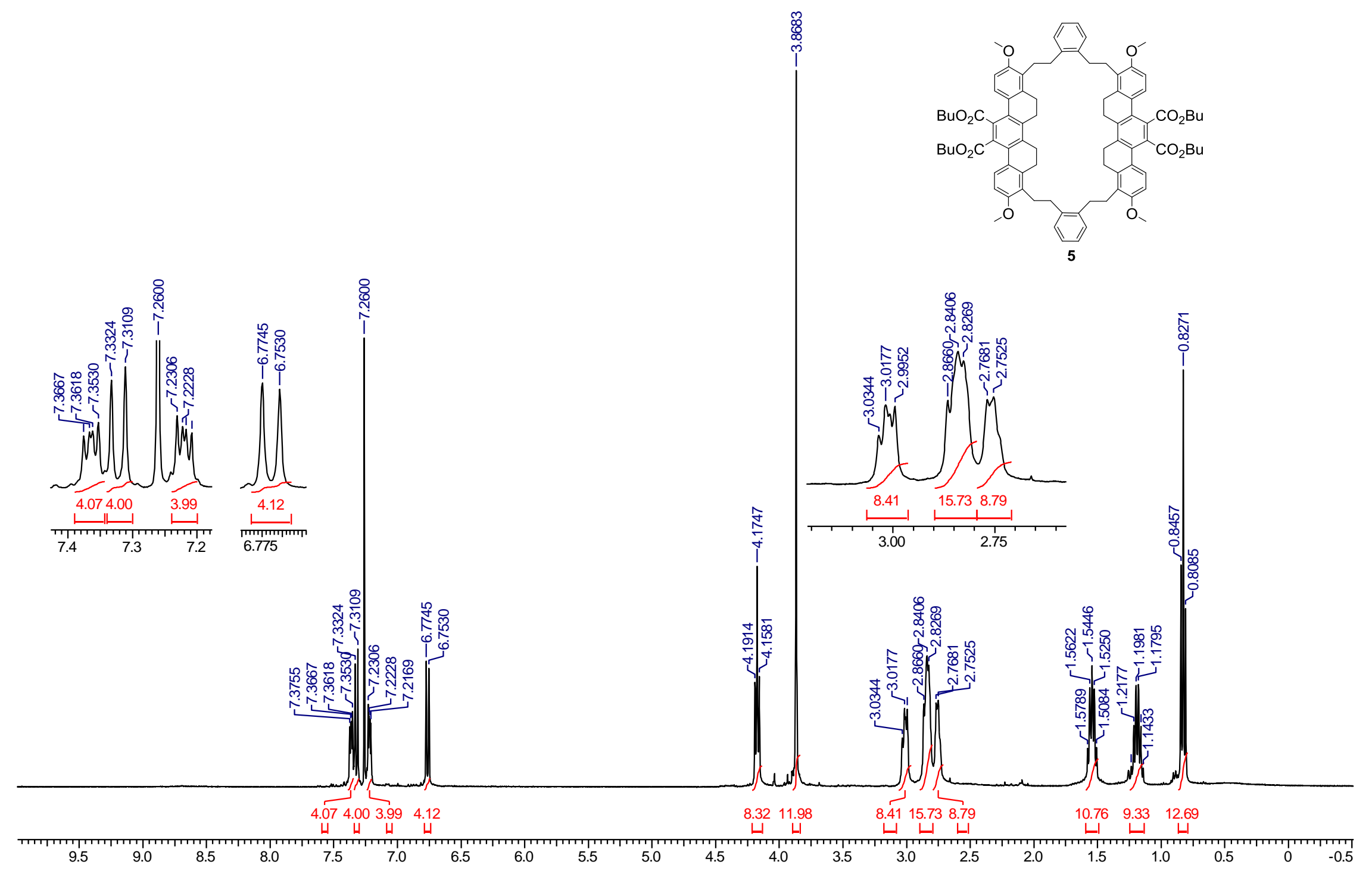




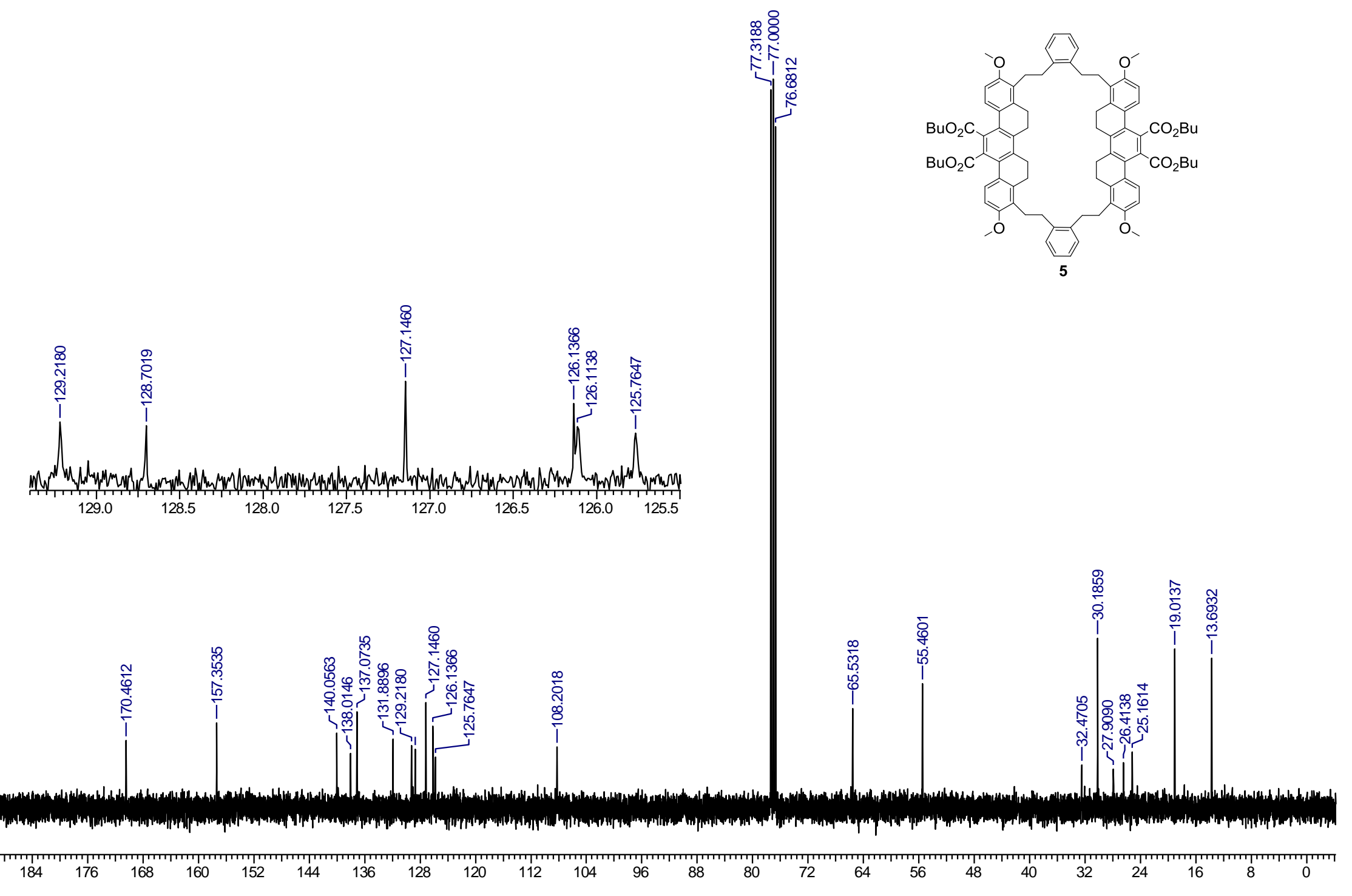

